\title{
A Simple Formula for Prediction of Compressive Strength of Square CFT Columns
}

\author{
Bassam Khulaif Alharbi ${ }^{(D)}$, Muhammad Aun Bashir ${ }^{*}$ (D) \\ Department of Civil Engineering, Imam Mohammad ibn Saud Islamic University, Riyadh, Saudi Arabia.
}

\section{Keywords}

CFT Column, Compressive Yielding Strength, $F E A$,

Composite Structure

\begin{abstract}
Concrete filled steel tube structures are becoming very popular in the modern civil engineering projects. Studying composite structures is useful, since it is an innovative and contemporary way to build structures. This type of structure has the ability to use respective strength of both steel and concrete due to confinement. Prefabrication of steel tube section is beneficial, and allows rapid installation into main structure. It also reduces the assembly cost and construction time. This paper will present the simple equation to predict the compressive strength of square concrete filled steel tube by using Finite Element Analysis (FEA)based software ABAQUs. In this study, 3D non-linear finite element models of short square composite columns were prepared using ABAQUS. The results were compared with published experimental tests of a concrete filled steel tube short columns. After getting the good agreement with the experimental results, a simple equation for the prediction of compressive strength is presented by considering the width to thickness ratio of steel tube. Results are validated with experimental results. The equation can predict the compressive strength only for the given material strengths and in future, the simple equation can be improved by considering different parameters e.g. material strength, slenderness ratio and end conditions.
\end{abstract}

\section{Introduction}

Studying composite structures is valuable since it is an innovative and contemporary way to build structures and benefit from different materials in a various way. Additionally, it will encourage future researchers to try and follow this approach. Composite columns are constructed using various combinations of structural steel and concrete to utilize the beneficial properties of each material. The steel carries the axial load and confines the concrete. Furthermore, the concrete doesn't need formwork, that will reduce the construction cost and time, and the concrete will take the axial load and delays the local buckling of the steel. There have been many research studies regarding thin-walled structures, including many geometric properties and types of loads [1].

Concrete-filled steel tubular (CFT) columns are being used in these days a lot, because of its advantages. Thus, they are used in many sectors like multi-story commercial buildings, bridges and industrial buildings. These composite structures provide earthquake resistant properties, such as high strength, high ductility, high stiffness, and large energy-absorption capacity. Due to their strong features, Bashir et al (2008) started research on Steel concrete composite structure system to develop the its design method. This type of structure has the potential to use respective strength of both steel and concrete due to confinement. Prefabrication of steel tube section is possible, and allows rapid installation into main structure. It also reduces the assembly cost and construction time [2]. Constitutive models for confined concrete are very important for the numerical simulation of these type of structures. Bashir et al. (2010) presented the modified equation for fracture energy of confined concrete for the simulation of post peak behavior of confined concrete [3]. Based on this modified stress strain model, parametric analysis on the moment anchorage capacity of concrete filled steel box footing (CFSB) was carried out by using the 3D finite element program CAMUI [4]. Bashir et al. (2016) presented the numerical simulation of axial anchorage capacity of
Concrete-Filled Steel Box Footing and results showed good agreement in terms of ultimate load capacity, but post-peak part of load deflection curve was not predicted precisely [5].

The main objective of this paper is to present the simple equation that will predict the compressive strength of square concrete filled steel tube by using Finite Element Analysis (FEA) based software ABAQUs.

\subsection{Current Code Provisions Review for Square CFT Columns}

Prediction of axial capacity of CFT columns described in different codes, are provided as follows.

The AIJ code (2001)

$$
\mathrm{N}_{\mathrm{AV}}=0.85 \mathrm{~F}_{\mathrm{cly}, 100} \mathrm{~A}_{\mathrm{c}}+1.27 \mathrm{~F}_{\mathrm{y}} \mathrm{A}_{\mathrm{s}}
$$

where $F_{\text {cly,100 }}=$ concrete compressive strength with $100 \times 200 \mathrm{~mm}$ cylinder tests; $\mathrm{Ac}=$ the cross-sectional area of the concrete; $\mathrm{As}=$ the cross-sectional area of the steel tube; and $F_{\mathrm{y}}=$ the yield stress of the steel tube.

The AISC code (2005)

When $P_{e} \geq 0.44 P_{\circ}$

$$
\begin{aligned}
& P o\left[0.658^{\frac{P o}{P e}}\right] \\
& \text { When } \mathrm{P}_{\mathrm{e}}<0.44 \mathrm{P} \text { 。 }
\end{aligned}
$$

NAISC $=0.877 \mathrm{P}_{\mathrm{e}}$

Where

$$
P_{o}=\text { Fy } A_{s}+0.95 F_{c l y, 150} A_{c}
$$




$$
\begin{aligned}
& P e=\frac{\pi^{2}(E I)_{e f f 1}}{(K L)^{2}} \\
& (E I)_{\text {eff } 1}=\mathrm{E}_{\mathrm{s} 1} \mathrm{I}_{\mathrm{s}}+\mathrm{C}_{3} \mathrm{E}_{\mathrm{c} 1} \mathrm{I}_{\mathrm{C}} \\
& \mathrm{C} 3=0.6+2\left(\frac{\mathrm{As}}{A c+A s}\right)
\end{aligned}
$$

where $f_{\text {cly,150 }}=$ concrete compressive strength with $150 \times 300 \mathrm{~mm}$ cylinder tests; $\mathrm{KL}=$ effective length of the column; $E_{\mathrm{s} 1}=$ the elasticity of the steel modulus $=2 \times 10^{5} \mathrm{MPa} ; \mathrm{E}_{\mathrm{c} 1}=$ elastic modulus of concrete $=$ $4730\left(f_{c l y, 150}\right)^{1 / 2}(\mathrm{MPa}) ;(\mathrm{EI})_{\text {eff1 }}=$ effective moment of inertia rigidity of composite section; and $I_{s}$ and $I_{c}=$ moment of inertia of steel tube and concrete core, respectively.

The Chinese Code DL/T (1999)

$$
\begin{aligned}
& N_{D L / T}=F_{s c y} A_{s c} \\
& A_{s c}=A_{s}+A_{c}
\end{aligned}
$$

\section{Methodology}

Various computer packages are available now a days and finite element analysis can be used with high accuracy. So due to the high accuracy, economy and multi-functional capability, ABAQUS was chosen for numerical simulation.

\subsection{Constitutive model For Steel}

The details of specimen are shown in Table 1. The stress-strain curve used for the steel tube is assumed to be elastic-perfectly plastic.

\subsection{Constitutive model for concrete}

The compression stress-strain model used for the concrete is the Modified Hognestad model shown in Figure 1. The tensile stressstrain curve used for the concrete is shown in Figure 2. Table 1 show the cross sections, geometry and material properties for square and rectangular $\mathrm{CFT}$, these specimens are modeled in ABAQUS according to details given in the experimental study by Schneider et al. [6].

Table 1. Properties of CFT Columns (Schneider et al.)

\begin{tabular}{|c|c|c|c|c|c|c|}
\hline Column & size & $\begin{array}{c}\mathrm{T} \\
(\mathrm{mm})\end{array}$ & $\begin{array}{c}\mathrm{B} / \mathrm{T} \\
(\mathrm{mm})\end{array}$ & $\begin{array}{c}\text { Length } \\
(\mathrm{mm})\end{array}$ & $\begin{array}{c}\mathrm{f}_{\mathrm{y}} \\
(\mathrm{MPa})\end{array}$ & fc (MPa) \\
\hline S5 & $\begin{array}{c}127 \times \\
127\end{array}$ & 7.47 & 17 & 609.6 & 347 & 23.8 \\
\hline R1 & $\begin{array}{c}76 \times \\
152\end{array}$ & 3 & 50.8 & 608 & 430 & 30.454 \\
\hline
\end{tabular}

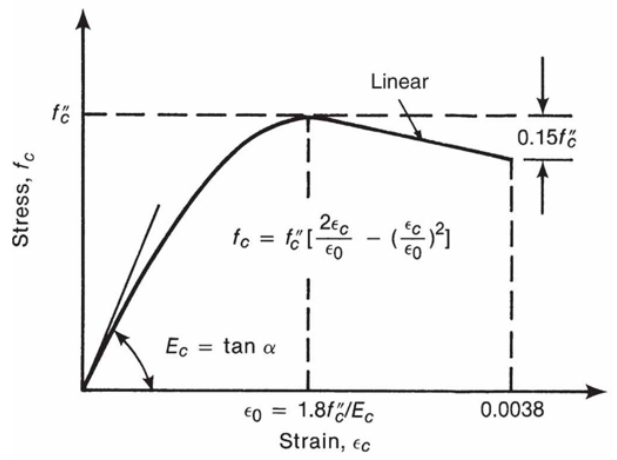

Figure 1 Stress-strain curve for concrete in compression (Modified Hognestad)

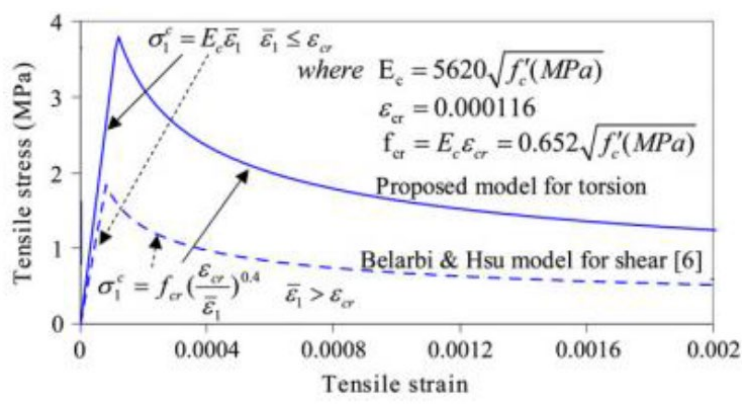

Figure 2 Tensile stress-strain curve of concrete

\section{Results and Discussions}

\subsection{Effect of changing mesh sizes on the load-deflection curve of R1:}

Different mesh sizes were used in the Rectangular column to study the effect of mesh sizes on the load-deflection curve of Rectangular column. A load deflection curve was plotted using different mesh sizes $(15,25$, and $30 \mathrm{~mm})$. Results are shown below in Figure 3

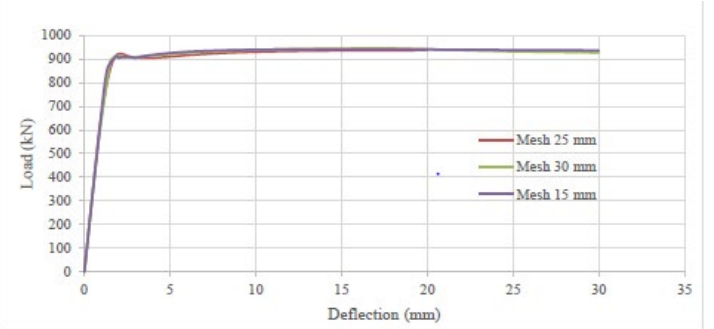

Figure 3 Load-def curve for different mesh size

As can be noted in Figure 3, the effect of changing mesh sizes on the load-deflection curve is very negligible. The critical stress $\left(F_{\mathrm{cr}}\right)$ was used instead of the yielding stress $\left(F_{y}\right)$ for steel in the ABAQUS.

\subsection{Using the critical stress $F_{c r}$ instead of Fy in R1 model:}

It can be noted in Figure 4; the yielding point was reduced as comparing to Figure 3. Therefore, use of critical stress $\left(F_{\mathrm{cr}}\right)$ for steel material in simulation, instead of the yielding stress $\left(F_{y}\right)$, shows good agreement with experimental results

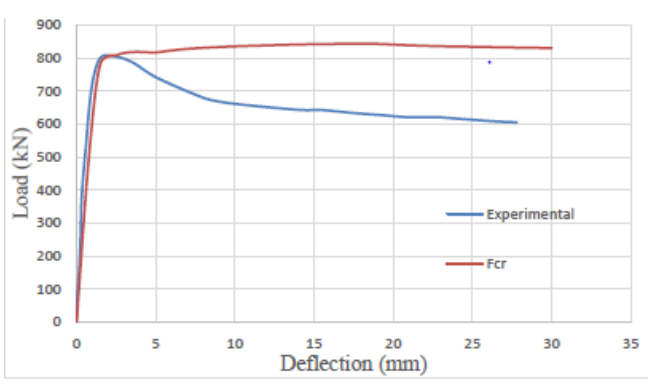

Figure 4 Load-def curve for using $F_{c r}$ 


\subsection{Effect of confinement pressure:}

A load-deflection curve by considering the normal concrete stress strain model for S5 was plotted and compared with the experimental load-deflection curve.

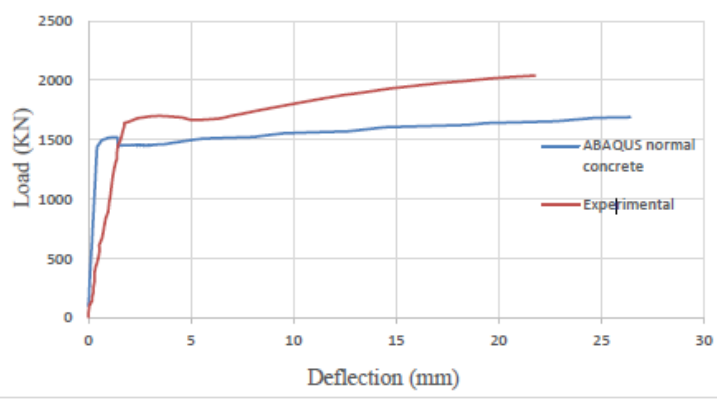

Figure 5 Load-def curve for using normal concrete stress strain model

As shown in Figure 5, the maximum load that causes a $20 \mathrm{~mm}$ deflection in the ABAQUS model is less than the experimental maximum load. These kinds of results were expected since the confinement effect was not considered. Therefore, the application of the confinement effect is necessary to produce realistic and similar results to the experimental study.

\subsection{The procedure of including confinement effect to S5:}

Therefore, to apply the confinement effect, the stress-strain model of the confined concrete had to be used. Mander et al. presented a stressstrain relation of confined concrete as shown below [7].

$$
f c=\left(\left(f^{\prime}{ }_{c c} x r\right) /\left(r-1+x^{r}\right)\right)
$$$$
f^{\prime}{ }^{\prime}=f^{\prime}{ }^{\prime}+k_{1} f_{l}
$$

$\left(k_{1}\right.$ is a function of the concrete mix and the lateral pressure, a value of 4.1 can be used as per Mander et al. [7])

$$
\begin{aligned}
& x=\varepsilon_{c} / \varepsilon_{c c} \\
& \varepsilon_{c c}=\varepsilon_{c o}\left[1+5\left(\left(f_{c c}^{\prime} / f^{\prime}{ }_{c o}\right)-1\right)\right] \\
& r=\left(E_{c} /\left(E_{c}-E_{s e c}\right)\right) \\
& E_{s e c}=\left(f^{\prime}{ }_{c c} / \varepsilon_{c c}\right)
\end{aligned}
$$

Where:

$f_{c c}=$ compressive strength of confined concrete,

$\varepsilon_{\mathrm{c}}=$ longitudinal compressive concrete strain,

$f_{c o}$ and $\varepsilon_{\mathrm{co}}=$ the unconfined concrete strength and corresponding strain,

$E_{c}=$ Young's modulus of concrete,

$E_{\text {sec }}=$ (secant) Young's modulus of concrete (approximately 0.7$\left.0.85 E_{c}\right)$.

The confining pressure for a square section was presented by Lingola et al. as following [8]:

$$
f_{l, s q}=\frac{4 \text { Esec Es ts } \varepsilon \mathrm{l}}{25 \operatorname{Esec} \mathrm{L}++12 \mathrm{Es} \text { ts }(5+2 v)}
$$

\section{Where:}

$E_{s}=$ Young's modulus for the steel wall,

$t_{s}=$ the thickness of the steel wall,
$\mathrm{L}=$ the half length of a side of the square cross-section,

$v=$ Poisson ratio (dilation ratio) at failure

$v$ was fixed equal to 0.2 . While more refined value can be based on the iterative evaluation

$\nu=\left(\varepsilon_{l} / \varepsilon_{c c}\right)$

\subsection{Applying the confinement effect to the square section:}

A value of the confining pressure $f_{1}$ had to be found, which is a function of different variables including $\varepsilon_{1}$ which is unknown. Therefore, in order to find a reasonable value of $\varepsilon_{\mathrm{l}}, \varepsilon_{\mathrm{cu}}$ was assumed instead of $\varepsilon_{\text {cc. }}$. It was assumed that the peak strain of the confined concrete approximately equal to ultimate strain of the normal concrete.

The value of $\varepsilon_{1}$ was calculated to be 0.006

$\varepsilon_{l}=v \varepsilon_{c u}=0.2 \times 0.003=0.0006$

Substituting in Equation (16):

$f_{l, s q}=0.41 \mathrm{MPa}$

Substituting in Equation (11):

$f^{\prime}{ }_{c c}=(21.4)+(4.1)(0.41)=23.07 \mathrm{MPa}$

Substituting in Equation (13)

$\varepsilon_{c c}=\varepsilon_{c o}[1+5((23.07 / 21.4)-1)]=0.00222$

Substituting in Equation (15), and Equation (14):

$E_{\text {sec }}=(23.07 / 0.00222)=10390.62$

$r=(23528 /(23528-10390.62))=1.7909$

Hence, in order to draw a stress-strain curve for the confined concrete, incremental values of strain were substituted in Equation (12) and then Equation (10) was used to draw the curve. Following is an example for a strain $=0.0002$ :

Substituting in Equation (12):

Thus, from Equation (10):

$f c=\left((23.07 \times 0.090079 \times 1.7909) /\left(1.7909-1+0.090079^{1.7909}\right)\right)=4.627$

The calculation was done using Microsoft Excel, the stress-strain model of S5 was found as shown in Figure 6.

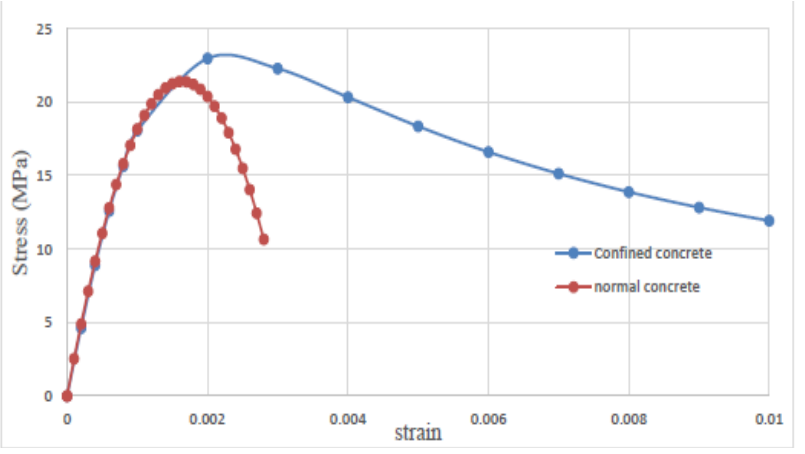


Figure 6 Stress strain curve for confined and normal concrete

As shown in Figure 6, the peak stress of the concrete was increased. Therefore, the effect of confined concrete was included in S5 model to improve the results obtained from normal concrete stress strain model. The constitutive model of the confined concrete was considered in ABAQUS and load-deflection curve was found for square section 55 as shown in Figure 7.

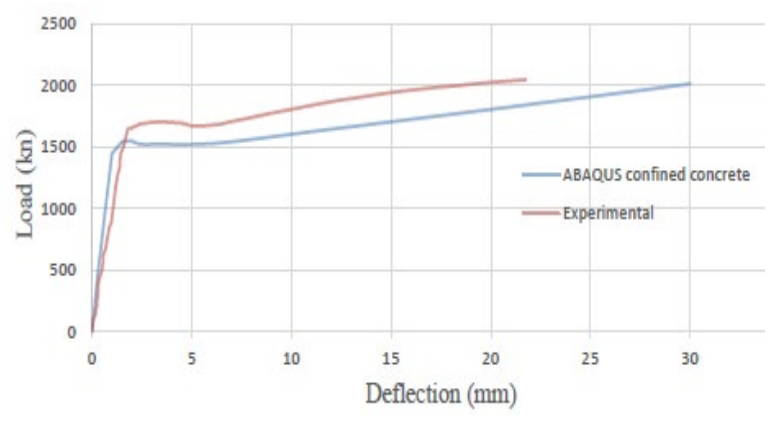

Figure 7 Load- deflection curve for S5

\subsection{Effect of changing $B / T$ ratio on the confinement pressure:}

Different models with square cross section were made by varying the $\mathrm{B} / \mathrm{T}$ ratios in order to study their effect on the load capacity. Details of the specimens for three cases are shown in Table 2.

Table $2 \mathrm{~B} / \mathrm{T}$ ratio for three cases

\begin{tabular}{ccc}
\hline \multicolumn{3}{c}{ For a fixed width $\mathrm{B}=127 \mathrm{~mm}$} \\
\hline Case/Thickness & $\mathrm{T}$ in $\mathrm{mm}$ & Ratio \\
Case 1 & 7.47 & 17 \\
Case 2 & 5 & 25.4 \\
Case 3 & 3 & 42.3 \\
\hline
\end{tabular}

Using the values in Table 2, a load - deflection curve was plotted for each case and the yielding load was recorded. Hence, a load B/T ratio curve was plotted to predict the simple equation for strength.

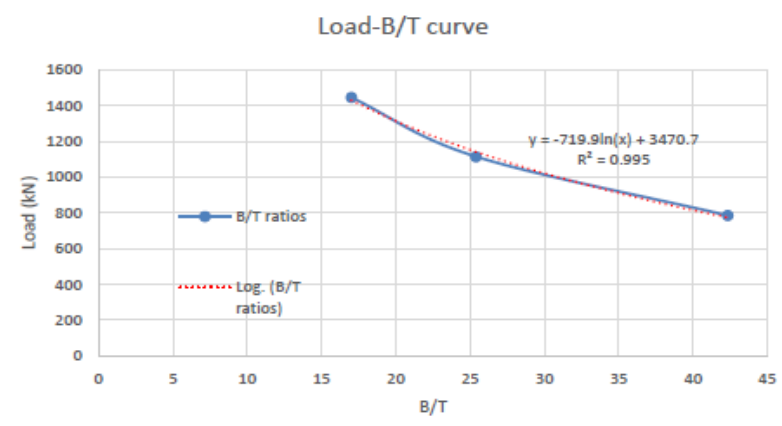

Figure 8 Load B/T curve

From Figure 8, it can be noted that the increase in $\mathrm{B} / \mathrm{T}$ ratio (by reducing the thickness) reduces the load capacity of the column. Additionally, a simple equation was developed to calculate the failure load for yielding of a section using $\mathrm{B} / \mathrm{T}$ ratio. The strength results calculated by this simple equation are compared with the experimental results and it shows reasonable agreement. (see Table 3)

$F=-719.9 \ln (x)+3470.7 \mathrm{kN}$.

(Where $x$ is the $\mathrm{B} / \mathrm{T}$ ratio).
Table 3 Comparison of experimental and equation results

\begin{tabular}{cccc}
\hline Column & B/T & $\begin{array}{c}\text { Experimental } \\
\text { yielding strength }\end{array}$ & $\begin{array}{c}\text { Yielding } \\
\text { strength from } \\
\text { formula }\end{array}$ \\
\hline SU-17 & 17 & 1600 & 1431 \\
SU-022 & 22 & 1200 & 1245 \\
SU-029 & 29 & 975 & 1047 \\
\hline
\end{tabular}

\section{Conclusions}

Following conclusions are made based on this study:

- $\quad$ Different mesh sizes do not affect the load-deflection curves of a model.

- A load-deflection curves of square composite column with confined concrete stress strain model shows good agreement with the experimental results.

- A simple equation for the prediction of compressive strength is presented by considering the width to thickness ratio of CFT column and results are validated with experimental results.

\section{Limitation of the equation}

The equation, developed in this paper, can predict the compressive strength only for the given material strengths.

In future, this equation can be improved by considering different parameters e.g. material strength, slenderness ratio and column end conditions.

\section{References}

[1.] Teng, G., Hu, Y.M., Behaviour of FRP-jacketed circular steel tubes and cylindrical shells under axial compression. Construction and Building Materials 21 (2007) 827-838.

[2.] Bashir, M.A., Furuuchi, H., Ueda, T., Parametric analysis of concrete filled steel box connection by using 3D finite element analysis. Journal of Structural Eng. JSCE 54A (2008)815-824.

[3.] Bashir, M.A., et al, Numerical simulation of ultimate capacity of steel Pile anchorage in concrete-filled steel box connection, Proceeding of JCI, 32(2) (2010) 1219-1224.

[4.] Bashir, M.A., et al, Prediction of ultimate moment anchorage capacity of concrete filled steel box footing. Steel and Composite Structures 15(6)(2013) 645-658

[5.] Bashir, M. A., et al, Numerical Simulation of Axial Anchorage Capacity of Concrete Filled Steel Box Footing. Iranian Journal of Science and Technology, Transactions of Civil Engineering 40(2016) 257-262.

[6.] Schneider, S., Axially Loaded Concrete-Filled Steel Tubes. Journal of Structural Engineering 124 (1998) 1125-1138.

[7.] Mander, J.B., et al, Theoretical Stress-Strain Model for Confined Concrete. Journal of Structural Engineering 114 (1988) 18041826.

[8.] Lingola, G. P., Prota A. Gaetano, M., Simplified Modeling of Rectangular Concrete Cross-Sections Confined by External FRP Wrapping. Polymers 6 (2014) 1187-1206.

[9.] JP Liu, TX Xu, YH Wang, Y Guo, Axial behaviour of circular steel tubed concrete stub columns confined by CFRP materials. Construction and Building Materials 168 (2018) 221-231.

[10.] Shariati M., et al, Numerical study on the axial compressive behavior of built-up CFT columns considering different welding lines. Steel and Composite Structures, 34 (2020)377-391.

[11.] Jeng C.H., T. T. H., A softened membrane model for torsion in reinforced concrete members. Engineering Structures 31 (2009) 1944-1954. 
[12.] Khan, H.U., Rafique, M.N., Karam, S., Ahmad, K., Bashir, A., Identification of Shear Cracks in Reinforced Beams Using Finite Element Method, Pakistan Journal of Science 66 (2014)50-55.

[13.] Ananya J., Kartha, U., Usha, S., , Analytical Study On StressStrain Behaviour Of Reinforced Concrete Column. International Journal of Civil Engineering and Technology 5 (2014)45-55.

\section{Declaration of Conflict of Interests}

The author(s) declare(s) that there is no conflict of interest. They have no known competing financial interests or personal relationships that could have appeared to influence the work reported in this paper.

\section{How to Cite This Article}

B. K. Alharbi1, M. A. Bashir, A Simple Formula for Prediction of Compressive Strength of Square CFT Columns. Civil Engineering Beyond Limits 1(2022), 1530. https://doi.org/10.36937/cebel.2022.1530 